\title{
APUNTES SOBRE LA GEOLOGÍA DE LAS HOJAS GOLFO Y BERRUGATE, COSTA RICA
}

\author{
Percy Denyer $^{1 *}$, Walter Montero ${ }^{1} \&$ Kennet Flores $^{2}$ \\ ${ }^{1}$ Escuela Centroamericana de Geología, Universidad de Costa Rica, \\ Apdo. 214-2060UCR, Costa Rica. \\ ${ }^{3}$ Institut de Géologie et Paléontologie, Université de Lausanne. \\ *Autor para correspondencia: pdenyer@geologia.ucr.ac.cr
}

\section{INTRODUCCIÓN}

Con la cartografía geológica de las hojas topográficas Golfo y Berrugate, se cubre una gran parte del golfo de Nicoya (Fig. 1). Se complementan, de esta forma, otros mapas publicados recientemente sobre esta región (Denyer \& Flores, 2003; Flores \& Denyer, 2003; Flores et al., 2003a, 2003b, 2003c). Todos estos mapas geológicos forman parte de un esfuerzo dirigido a entender la evolución geológica del NW de Costa Rica, previamente iniciado por otros autores como Dengo (1962), Kuijpers (1980) y Astorga (1987).

El golfo de Nicoya es un estuario alargado con una dirección NW, un ancho de unos $20 \mathrm{~km}$ y un largo de $60 \mathrm{~km}$. Dentro del golfo existen más de 10 islas y un sinnúmero de islotes, algunas islas con una población humana importante. La isla de mayor tamaño es la de Chira, con una longitud de más de $10 \mathrm{~km}$.

En estos dos mapas se incluye tanto el trabajo de campo de los autores, así como una síntesis de publicaciones e informes inéditos de la Escuela Centroamericana de Geología (Campo II, 1994; Campo II, 1997; Denyer et al., 1987;

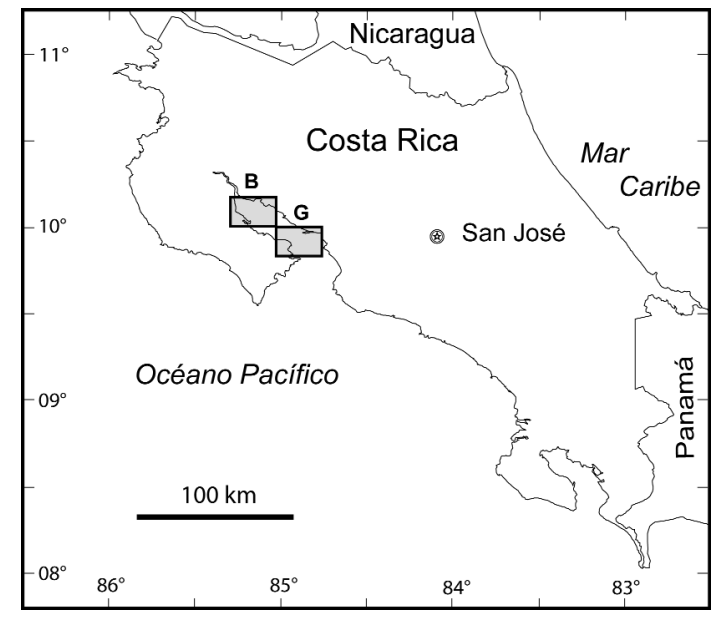

Figura 1: Mapa de localización, B: Hoja Berrugate, G: Hoja Golfo.

Denyer et al., 1990), dentro de un modelo conceptual estratigráfico previamente establecido para la cobertura sedimentaria del complejo de Nicoya (Denyer \& Flores, 2003; Flores, 2003; Flores et al., 2003a, 2003b y 2003c), que a su vez se basó en dos trabajos fundamentales de Dengo (1962) y Astorga (1987). 
Aquí se presentan cambios novedosos con respecto a los mapas regionales existentes (Dengo, 1962; MIEM, 1982; Fernández, 1997; Tournon \& Alvarado, 1997) con lo cual se actualiza la base cartográfica geológica de Costa Rica. Se da especial atención a las islas e islotes, pues pocos trabajos geológicos han abarcado previamente las islas (p.ej. Dóndoli, 1967; Bergoeing, 1977; Campo II, 1994; Arredondo et al., 1995; Campo II, 1997; Flores, 2003).

Todas las unidades geológicas que se cartografiaron en las hojas Berrugate y Golfo son unidades formales previamente descritas (Dengo, 1962; Astorga, 1987; Flores, 2003; Flores et al., 2003a, 2003b) por lo que se hará solo una descripción sencilla de cada unidad. Las descripciones completas pueden consultarse en los trabajos originales.

\section{UNIDADES GEOLÓGICAS}

Complejo de Nicoya: Aflora en los extremos NE y SW de la hoja Berrugate y en las islas Caballo y Cedros de la hoja Golfo. Corresponde con una secuencia de basaltos toleíticos y brechas basálticas más antigua que el Campaniano-Santoniano (Dengo, 1962; Kuijpers, 1980). Los basaltos son masivos y en almohadilla. Destacan las brechas basálticas, en contacto con las rocas de cobertura de la Formación Berrugate en la isla Cedros.

Formación Loma Chumico: Aflora en el extremo SW de la hoja Berrugate, al S del poblado de San Pablo. Está constituida por sedimentos silíceos y bituminosos del Albiano Superior, según la descripción original de Azéma et al. (1979). Ha sido estudiada por Calvo \& Bolz (1994), Astorga (1997), Calvo (1998, 2003). Flores (2003) y Flores et al. (2003a). Sin embargo, Flores (2003) y Flores et al. (2003a) restringen esta unidad a los sedimentos bituminosos albianos, separando los sedimentos silíceos verdes, bituminosos como Formación Berrugate.

Formación Berrugate: En la hoja Berrugate aflora en la isla del mismo nombre, que es donde se ubica su localidad tipo, y en las cercanías de
Manzanillo. Sobreyace inconformemente a los basaltos del Complejo de Nicoya, también existen unos afloramientos en el extremo NW de la isla Bejuco. En la hoja Golfo se observan claramente sobreyaciendo a los basaltos y brechas del Complejo de Nicoya en las islas Cedros y Caballo, donde forman una secuencia decamétrica que buza hacia el N. Estas islas fueron descritas anteriormente con otros conceptos litológicos (Dengo, 1962; MIEM, 1982; Astorga, 1987; Fernández, 1997; Tournon \& Alvarado, 1997). La formación Berrugate está constituida por unos $60 \mathrm{~m}$ de lodolitas silíceas verdes, lodolitas bituminosas, wackes líticas, lodolitas tobáceas, ignimbritas submarinas y brechas. Su edad se interpreta, con base en las relaciones estratigráficas, como Cenomaniano Superior-Turoniano Inferior. Fue definida formalmente por Flores et al. (2003a), quien la separa de la Formación Loma Chumico, como se menciona anteriormente, y por lo tanto, varias de las descripciones de Astorga (1997) y Calvo $(1998,2003)$ corresponden a esta nueva unidad.

Formación Sabana Grande: Aflora en la isla Bejuco, en el SE de la hoja Berrugate. Está compuesta por sedimentos silíceos y carbonatados de origen pelágico, hemipelágico y turbidítico, cuya edad probablemente corresponde al Cenomaniano-Coniaciano. De la definición original hecha por Dengo (1962), Flores et al. (2003a) separan las calcilutitas blancas y rosadas de esta unidad y las ubican en una nueva formación, denominada Piedras Blancas, que no aflora en las hojas Berrugate y Golfo.

Formación Coyolito: Aflora en el extremo NE de la hoja Berrugate. Esta unidad geológica está constituida por secuencias de lutitas rojizas y violáceas con intercalaciones milimétricas y centimétricas de areniscas finas gris verdosas; seguido por una secuencia de intercalaciones centimétricas de lutitas violáceas y areniscas finas gris verdosas, ambas silíceas. Esto modifica la adscripción previamente establecida por Denyer et al. (1987) y Denyer et al. (1990) como Formación Rivas. La Formación Coyolito fue descrita por Flores et al. (2003b) y se presume 
que se formó en el Cretácico Superior, probablemente Campaniano Inferior.

Formación Curú: Aflora en la parte SW de la hoja Golfo. Litológicamente corresponde con intercalaciones cíclicas de areniscas y lutitas, con algunos conglomerados. Su composición es volcaniclástica y sedimentológicamente corresponden con turbiditas, con una edad Maastrichtiano Medio/Superior a Paleoceno Superior basal (Astorga, 1987). Originalmente, estas litologías fueron descritas por Dengo (1962) para la península de Nicoya como Formación Rivas, unidad definida por Zoppis-Bracci \& DelGiudice (1958) en el sur de Nicaragua.

Formación Descartes: Es la unidad geológica de mayor distribución en las dos hojas cartográficas. En la hoja Berrugate aflora en las cercanías de Manzanillo (Denyer et al., 1987; Denyer et al., 1990) y la isla Chira (Campo II, 1994). En la hoja Golfo está presente en el borde SW del golfo de Nicoya (Astorga, 1987) y en la isla San Lucas (Campo II, 1997). Litológicamente está compuesta por intercalaciones cíclicas de tres tipos: areniscas medias grises, intercalaciones centimétricas de lutitas y areniscas finas calcáreas con horizontes de calizas masivas, calizas bioclásticas, calcarenitas, brechas y conglomerados calcáreos, y calcarenitas y calizas (Flores, 2003; Astorga, 1987). Está compuesta por secuencias de sedimentos turbidíticos volcanoclásticos y carbonatados del Paleoceno Superior a Eoceno Superior/Oligoceno Inferior (Astorga, 1987). Originalmente, estas litologías habían sido descritas como parte de las formaciones Brito y Las Palmas (Dengo, 1962). El trazo de su contacto basal, concordante con la Formación Curú ha sido modificado en la hoja Golfo, después de los mapas originales de Dengo (1962) y Astorga (1987).

Miembro Cerco de Piedra: Aflora en el extremo W de la isla Chira, hoja Berrugate. Corresponde con conglomerados de fragmentos volcánicos andesíticos, calizas y pedernales. Su selección es de regular a mala y presentan matriz arcillosa a limo arenosa con cemento calcáreo
(Sprechmann, 1982). Corresponde con sedimentos arenosos y conglomerádicos de origen turbidítico (Sprechmann, 1982; Flores et al., 2003b). Rivier (1983) le asigna una edad Paleoceno Medio a Superior. Por primera vez, el sector occidental de la isla Chira es asociado a esta unidad geológica, aunque en Campo II (1994) ya había sido distinguida como una unidad diferente.

Depósitos aluviales y coluviales: Los depósitos aluviales corresponden con rellenos cuaternarios en las zonas cercanas a la costa, donde los ríos cambian su régimen erosivo y sedimentan parte de su carga, así como algunos depósitos de gravedad (coluviales).

Depósitos fluvio-marinos: Corresponden con los depósitos actuales de interacción marino fluvial, que se forman directamente en la línea de costa y que incluyen marismas, pantanos y manglares.

Depósitos de barra arenosa: La ciudad de Puntarenas (hoja Golfo) corresponde con una barra arenosa, desde un punto de vista geológico y, geomorfológicamente, se considera una flecha, cuya formación es muy reciente, probablemente durante el período histórico. Es una lengüeta de $10 \mathrm{~km}$ de largo con una dirección prácticamente $\mathrm{E}-\mathrm{W}$, con su punta al $\mathrm{W}$, ligeramente combada al SE en su extremo occidental; su ancho máximo es de $600 \mathrm{~m}$, mientras que la zona más angosta tiene unos $50 \mathrm{~m}$ en La Angostura; su altura máxima es de unos $3 \mathrm{~m}$.

\section{ASPECTOS ESTRUCTURALES}

Por primera vez se describe el detalle del fallamiento y plegamiento de las islas San Lucas y Chira, y se cartografían las trazas de fallas siniestrales con direcciones E-W y WNW-ESE que limitan el golfo de Nicoya. El origen de este fallamiento y plegamiento es todavía un punto de discusión geológica. Sin embargo, en este trabajo se presentan los hallazgos de campo, como punto de partida para un debate ulterior acerca del origen y evolución, tanto de la península como del golfo de Nicoya, lo cual se está llevando a cabo a 
través del proyecto 113-A5-162 de la Vicerrectoría de Investigación de la Universidad de Costa Rica.

Plegamiento: En la hoja Golfo destacan los pliegues de la isla San Lucas, principalmente sinclinales con ejes E-W y WNW-ESE, buzantes al E (Dóndoli, 1967; Dengo, 1962; Campo II, 1997). La isla Chira (hoja Berrugate) corresponde con un sinclinal (Dengo, 1962; Bergoeing, 1977; Campo II, 1994), ligeramente asimétrico, cuyo eje es WNW-ESE, cóncavo hacia el N.

Fallamiento: En la hoja Berrugate destaca la falla Morote, de dirección WNW-ESE y cuyo movimiento se ha interpretado preliminarmente como siniestral. Otras fallas NW se infieren en el golfo, basados en otros trabajos (Flores \& Denyer, 2003; Flores et al., 2003c). Las fallas del NE de la hoja Berrugate se interpretan con base en Denyer et al. (1987) y Denyer et al. (1990). En la hoja Golfo destacan las fallas siniestrales E-W, que en algunos casos se curvan al SW-NE, hacia el W de la hoja. La falla NE-SW que divide la isla Cedros de tierra firme se infiere en forma conceptual, debido a la interrupción abrupta de la Formación Descartes, contra unidades más antiguas en la isla Cedros. Otras fallas en la isla San Lucas vuelven discontinuo el plegamiento presente.

\section{AGRADECIMIENTOS}

Esta publicación es un resultado de los proyectos 113-90-071, 113-A5-047 y 113-A5-162 de la Vicerrectoría de Investigación de la Universidad de Costa Rica. Gran parte del trabajo en la zona costera se hizo en colaboración con el Dr. Jorge Cortés del Centro de Investigaciones en Ciencias del Mar y Limnología (CIMAR).

\section{REFERENCIAS}

ARREDONDO, S., LOSILlA, M. \& RODRÍGUEZ, H., 1995: Reconocimiento hidrogeológico en la Isla San Lucas, Puntarenas, Costa Rica. - 13 págs. UCR-
RELAU-SENARA-AyA-DRIP, San José [Informe interno no publicado].

ASTORGA, A., 1987: El Cretácico Superior y el Paleógeno de la vertiente pacífica de Nicaragua meridional y Costa Rica septentrional: origen, evolución y dinámica de las cuencas profundas relacionadas al margen convergente de Centroamérica. - 250 págs. Univ. de Costa Rica [Tesis Lic.]

ASTORGA, A., 1997: El puente-istmo de América Central y la evolución de la placa Caribe, con énfasis en el Mesozoico. - Profil, 12: 1-201.

AZÉMA, J., J. TOURNON \& SORNAY, J., 1979: Precencia de amonites del Albiano Superior en las Formaciones del "Complejo de Nicoya". El yacimiento de la Loma Chumico, Provincia de Guanacaste, Costa Rica. - Inf. Semestral I.G.N. 1979(2): 71-76.

BAUMGARTNER, P. O., C. R. MORA, J. BUTTERLIN, J. SIGAL, G. GLACON, J. AZEMA \& BOURGOIS, J., 1984: Sedimentología y paleogeografía del Cretácico y Cenozoico del litoral pacífico de Costa Rica. - Rev. Geol. Amér. Central, 1: 57-136.

BERGOEING, J.P., 1977: Aspectos geomorfológicos de la Isla de Chira, Costa Rica. - Inf. Semestral I.G.N. 1977(2): 45-51.

CALVO, C., 1998: Kretazische Subduktionsprozesse in Südzentralamerika. - Profil, 15: 1-161.

CALVO, C., 2003: Provenance of plutonic detritus in cover sandstones of Nicoya Complex, Costa Rica: Cretaceous unroofing history of a Mesozoic ophiolite sequence. - Geol. Soc. Amer. Bull. 115(7): 832-844.

CALVO, C. \& BOLZ, A., 1994: Der älteste InselbogenVulkanismus in Costa Rica, Marine Pyroklastika der Formation Loma Chumico (Alb bis Campan). - Profil, 7: 235-264.

CAMPO II [ALPÍZAR, R., ARIAS, M., BRENES, W., MORA, M., SALAZAR, J., VARGAS, I. \& DENYER, P.], 1994: Estudio geológico integral de la isla Chira, Puntarenas, Costa Rica. - 43 págs. Univ. de Costa Rica [Inf. de curso Geología de Campo II].

CAMPO II [CHAVARÍA, L., MONROE, R., PÉREZ, W., ROJAS, M., SIBAJA, G. \& DENYER, P.], 1997: Geología de la isla San Lucas, Puntarenas, Costa Rica. - 33 págs. Univ. de Costa Rica [Inf. de curso Geología de Campo II].

DENGO, G., 1962: Estudio geológico de la región de Guanacaste, Costa Rica. - 112 págs. Inst. Geogr. Nacional, San José. 
DENYER, P., MONTERO, W., SOTO, G., QUEZADA, A., LEANDRO, L., PEREZ, C. \& RODRIGUEZ, D., 1987: Geología y tectónica de la margen oriental del Golfo de Nicoya, C.R. - Cienc. Tec. 9(2): 17-31.

DENYER, P. (ed.), MONTERO, W., BARRIOS, L., CALERO, A., CASTRO, A., COSILLO, A., FERNÁNDEZ, M., LEANDRO, L., MORÁN, G., PÉREZ, C., QUESADA, A., RÍOS, D., RODRÍGUEZ, D., ALFARO, A., PERALDO, G., SALAZAR, L., BARRANTES, M. \& PÉREZ, R. 1990: Detalles sobre la geología de Punta Morales-CoyolitoManazanillo. - Rev. geól. Amér. Central (11): 91-95.

DENYER, P. \& FLORES, K., 2003: Mapa geológico de la hoja Talolinga. - Rev. Geol. Amér. Central, 28, Serie: Colección de mapas geológicos 2 (Escala 1: 100 000).

DÓNDOLI, C., 1967: Estudio geológico y mineralógico pedológico de la Isla de San Lucas. - 46 págs. Ministerio de Agricultura e Industrias, San José.

FERNÁNDEZ, A., 1997: Mapa geológico de Costa Rica. Escala 1:750 000. Ministerio del Ambiente y Energía y Refinadora Costarricense de Petróleo, San José.

FLORES, K., 2003: Propuesta tectonoestratigráfica de la región septentrional del golfo de Nicoya, Costa Rica. 176 págs. Univ. de Costa Rica [Tesis Lic.]

FLORES, K., DENYER, P. \& AGUILAR, T., 2003a: Nueva propuesta estratigráfica: Geología de las hojas Matambú y Talolinga, Guanacaste, Costa Rica. - Rev. Geol. Amér. Central, 28: 131-138.

FLORES, K., DENYER, P. \& AGUILAR, T., 2003b: Geología y estratigrafía de la hoja Abangares,
Guanacaste, Costa Rica. - Rev. Geol. Amér. Central, 29: 127-136.

FLORES, K., DENYER, P. \& AGUILAR, T., 2003c: Mapa geológico de la hoja Abangares. - Rev. Geol. Amér. Central, 29, Serie: Colección de mapas geológicos 4 (Escala 1: 100 000).

FLORES, K. \& DENYER, P., 2003: Mapa geológico de la hoja Matambú. - Rev. Geol. Amér. Central, 28, Serie: Colección de mapas geológicos 1 (Escala 1: 100 000).

KUIJPERS, E., 1980: The geologic history of the Nicoya Ophiolite Complex, Costa Rica. - Tectonophysics, 68: 233-255.

MIEM, 1982: Mapa geológico de Costa Rica. - Escala 1: 200 000, I.G.N., San José.

RIVIER, F., 1983: Síntesis geológica y mapa geológico del área del Bajo Tempisque, Guanacaste, Costa Rica.Inf. Semestral, I.G.N. 1983(1): 7-30.

SPRECHMANN, P., 1982: Estratigrafía de Costa Rica (América Central), I: unidades estratigráficas sedimentarias. - Actas V Cong. Latinoamericano Geol. Buenos Aires, I: 55-71.

TOURNON, J. \& ALVARADO, G., 1997: Mapa geológico de Costa Rica, folleto explicativo. - 79 págs. + mapa escala 1:500 000, Editorial Tecnológica de Costa Rica, Cartago.

ZOPPIS-BRACCI, L. \& DEL GIUDICE, D., 1958: Geología de la costa del pacífico de Nicaragua. - Bol. Servicio Geol. Nac. de Nicaragua, 2: 21-68. 